\title{
CORRESPONDENCE
}

\section{OXYPHENONIUM AS AN ATROPINE SUBSTITUTE}

\section{To the Editorial Committee of the British Journal of Ophthalmology}

SIRS-In my recent article on the use of oxyphenonium as an atropine substitute (Roper-Hall, 1957) I stated that a previous atropine substitute, Lachesine, had been withdrawn from production. This was true at the date when the article was written in November, 1956, but I have recently learned that Lachesine is now being manufactured again.

139 MOOR Green LANE,

Yours faithfully, M. J. ROPER-HALL. MOSELEY, BIRMINGHAM, 13. March 14, 1957.

\section{REFERENCE}

ROPER-HALL, M. J. (1957). British Journal of Ophthalmology, 41, 238.

\section{BOOK REVIEW}

The Visual Fields. A Text-book and Atlas of Clinical Perimetry. By David $O$. HarRINGTON. 1956. Pp. 327, 234 illus., 9 col. pl., bibl. Kimpton, London. (f6).

The value of perimetry in ophthalmology and particularly in neuro-ophthalmology has been fully established, but as long as it is considered a dull and boring procedure for examiner and patient alike, full use will not be made of the method. The reader of this book will surely find his interest stimulated and will feel challenged by the problems presented to a livelier appreciation and application of perimetry.

In spite of the fact that the author has been instrumental in developing several new and valuable methods, he emphasises again and again that the apparatus is of minor importance, and that "the man behind the perimeter is more important than the equipment he uses".

The first section of the book is concerned with technique and gives much useful advice on using such simple methods as confrontation. The standard perimeters and tangent screens are described and special techniques, such as angioscotometry, ultra-violet light with fluorescent test objects, and flicker fusion fields, are described in detail. A multiplepattern method, using fluorescent targets for rapid routine field testing, is particularly interesting, and would be very suitable for screening large numbers of patients. The test can be done by a nurse or technician with the minimum of training and, while in no sense replacing ordinary methods, might well become a part of every routine ophthalmological examination.

The anatomy of the visual pathways is described very lucidly with the aid of excellent anatomical drawings and diagrams. The normal visual field is compared to an island hill of vision surrounded by a sea of blindness, after the manner of Traquair, whose influence throughout the book is acknowledged by his one-time pupil.

The physiological and psychological influences on the size of the fields are carefully pointed out and the necessity of adapting one's methods to the individual patient is emphasized. 